\title{
Expanding on \#YouDoYou: Reflections from the 2015 Cohort of 3M National Student Fellows on Exploring Authenticity in Education
}

\author{
Justine Baek, Western University \\ Wali Shah, University of Toronto \\ Vrindy Spencer, Quest University Canada \\ Piper Riley Thompson, Mount Allison University \\ Karen Young, University of Toronto \\ Aniqah Zowmi, Brock University
}

The fourth cohort of $3 M$ National Student Fellows explores the current state of our post-secondary education system across Canada and opportunities to further tune into practice in order to pursue an authentic and meaningful academic life. Six of the 20153 M National Student Fellows propose recommendations for decision-makers at post-secondary institutions across Canada to challenge the status quo through embracing varied methods of teaching and learning.

\section{Overview}

$\mathrm{T}$ he six contributors to this article represent the 2015 3M National Student Fellows of Canada, the fourth cohort of undergraduates recognized for embracing a vision of education beyond what is traditionally offered in their respective universities. This article expands on the wide range of perspectives and common, underlying themes that were explored by the 3M National Student Fellows during their retreat and plenary at the Society for Teaching and Learning in Higher Education (STLHE)'s 35th annual conference in June 2015 in Vancouver, British Columbia. Our experiences are described in a series of essays that complement current literature on higher education by illuminating how educational gaps discussed in literature play out in lived experiences. Much like the cohorts before us, our belief is that post-secondary institutions and educators can develop more innovative approaches to education by fostering options for self-directed learning environments, encouraging opportunities to learn from mistakes, integrating arts-based evaluation and equitable assessment, fostering mentorship opportunities driving student-to-student impact, as well as designing passion into all aspects of the education experience. It is an honour to bring to the educational sphere the vast experiences and diversity of opinions of the 3M National Student Fellows.

\section{Introduction}

We live in a rapidly changing society; the Canadian labour force is progressively aging, fertility rates and life expectancy are decreasing, and the baby boomer generation is exiting the workforce (McMullin, Cooke, \& Downie, 2004). The bulk of the responsibility to ensure students possess the relevant skills and experience to flourish in today's workforce and society falls upon post-secondary institutions. Examples of these struggles can be seen in the somewhat slow adaptation of pedagogies and assessments attuned to practical or performative- 
expressive experiences, digital literacies, and multiple modalities of learning (Frost and Connolly, 2015). Amidst discussions to address these challenges and adapt to a changing social and economic landscape, the voice of post-secondary students is quintessential in decisions made to improve and build upon higher education; students speak from personal experiences that may or may not reflect the aims of current policies and goals of decision-makers in higher education. As the $20153 \mathrm{M}$ National Student Fellowship cohort, we are privileged to have this valuable opportunity to speak intimately on topics that reflect the array of our own diverse experiences from student communities across Canada. This paper articulates reflective statements on learning and advocates for student interests and priorities in higher education. We propose broadening student opportunities for learning, providing flexibility within our academic environments, and challenging students to find their passions within the academic sphere. Our work is presented with the aim of expressing student insight on gaps in higher education often discussed in a detached perspective in the academic literature. We call for institutions to be willing to entertain changes that propose broader student opportunities for learning, provide flexibility within our learning environments, and challenge us to find and nurture our passions.

\section{Essays}

\section{Talking About the " $\mathrm{F}$ " Word}

Piper Riley Thompson

When I mention the $\mathrm{F}$ word in this piece, I am talking about Failure. That "f" word means different things to each person, yet its power influences and informs our lives. Certainly my personal and public failures have come in many forms. At the time of each occurrence, I genuinely felt as though the world was closing in around me; my view of a "successful" future diminished with each passing moment. I wish now that in those moments of despair, I could have realized how instrumental these failures would be in shaping the rest of my life.
In many of my experiences within academic institutions, failure is not only discouraged, it is practically forbidden. I was counselled to shy away from courses in which I would not expect to earn a competitive mark. My generation seems to always be working towards something bigger, brighter, and more impressive - without ever stopping to reflect on what we are learning during our race to the top. I ran away from failure. I avoided it at all costs, and I strongly believed that no good could ever come from being knocked down by something I considered a failure. I could not have been more wrong.

If I have learned anything during my undergraduate degree, it is the following: in order to have authentic educational experiences, we must have opportunities to fail. In the fall semester of 2014, I received a mark of $\mathrm{C}$ - in a course. For me, this was a significant failure and at the time, nothing seemed more devastating. Over time, this failure was incredibly liberating and gave me the opportunity to reevaluate and refocus the ways in which I view and approach my education. This experience allowed me to become the leader of my own education. I now focus less, or not at all, on reaching an unattainable version of academic perfection and instead exert my energy into creative risk-taking. I thought this Cwould define me in crushing ways; instead, it has taught me how to be more compassionate with myself, how to understand the power of creativity in academia, and how important it is to take meaningful risks.

I am working now toward achieving expanded and textured notions of leadership. At the university I attend, on-campus and community leadership contributes significantly to campus culture. Throughout my education I have witnessed, interacted with, and learned from many different types of leaders. In both formal and informal educational events I have attended on leadership, failure is rarely mentioned, except in relation to its being something horrible - something to be avoided at all costs.

However, from a young age, my parents instilled in me that "all work is honourable." My experience with failure allowed me to recover this wise and humbling understanding of self and of leadership. Educational leaders allow themselves the 
opportunities to fail and learn from their mistakes. They are not reduced to the polished $\mathrm{CV}$, the LinkedIn profile page, or their email signature. These kinds of official self-representations do not provide room for important claims such as "did not get the part in the school play," or "ran for elected office, and lost." The moments and periods of time when I have experienced failure have had more profound effects on my life than what some might consider my greatest successes precisely because I have been able to get in touch with a more authentic and complex rendering of who I am.

I imagine a higher education system in which mistakes are not only allowed but encouraged. Mistakes lead to failures, both big and small, and they foster environments in which powerful and transformational learning occurs. Leadership and leaders within post-secondary education come in many forms. Some of the greatest leaders I know are not those with the greatest titles; rather, they are the people taking risks, who are not afraid to make mistakes and to fail outright. Professors in higher education also wonder about the need for failure and ways to create environments for their grade-anxious students to take the risks that might lead to transformative learning (Siering, 2012; Orlando, 2011). I believe that welcoming failure and new notions of leadership into our academic environments will allow us to practice and appreciate bravery in ourselves and in those around us.

\section{Creating a Space for Exploration and Experimentation: Classroom-Based Pedagogies of Engagement}

Justine Baek

As a fourth year student preparing for graduation, I have learned through my post-secondary experiences that there are many ways one can learn. Most of my education comprised of didactic lectures, which established the foundations of my knowledge. However, without a doubt, the experiences that I will vividly remember long after I graduate are the activities that engaged me in the lesson by challenging me to integrate knowledge from different disciplines, testing my abilities in critical thinking and problem- solving, and providing me insight into the purpose of what I was learning in the classroom. These experiences empowered and inspired me to learn. Reflecting on these experiences, I wonder if today's conventional classrooms cannot evolve to engage students in the learning experience and put the learner at the centre of the classroom, to encourage students to take an expanded and more active role in education.

The importance of student engagement in the classroom is not a novel idea; an assessment study of Harvard University students by Light (1992) showed that one of the most important factors determining the educational growth and development of an undergraduate student is the extent to which they are actively involved in classroom work. Pascarella and Terenzini (1991) describe numerous teaching strategies that can be employed in the classroom to increase student engagement in learning, enhance knowledge acquisition, and stimulate cognitive changes and development; the number of methods is continuously increasing.

Encouraging collaborative learning is one method that has been used to immerse learners in the classroom lesson, and has also provided students the opportunity to problem-solve, think critically, and most importantly, work with a diverse group of peers to complete a complex task or to resolve a case. My own involvement with collaborative learning was in a seminar style course with 30 students, in which students were tasked each week to reflect on global ethical issues by analyzing them from social, moral, and political perspectives in a format that combined elements of both case-based and problem-based learning. It was rewarding to be able to work with my colleagues and learn from their unique scholarship, skills, and experiences to solve a problem. Discussing knowledge learned in class enabled me to internalize the information, and tackling real world cases made it easier for me to connect and translate that information into knowledge that could be applied to practical real-world problems. Other students have had similarly positive learning experiences with collaborative case-based learning, and educators have only recently begun to recognize how working collaboratively can push students to perform at higher 
intellectual levels and can foster the development of key critical thinking skills (Gokhale, 1995; Vygotsky, 1978).

Experiential learning is another type of learning that has only recently begun not only to be offered to students as extra-curricular learning opportunities, but also to be incorporated formally into college and university curricula. The integration of experiential learning into the classroom provides students the opportunity to apply, first-hand, their knowledge from lectures for practical purposes (Cantor, 1997). My own experiential learning was facilitated through a supervised research course for which I earned full course credit. As part of the course, I performed an independent research project investigating the development of an HIV-1 therapeutic vaccine. Earning a credit for this type of learning experience enabled me to enroll in it as part of my course load. Not having to do a course overload made it easier for me to gain valuable skills performing hands-on scientific research. In addition, for the course's final evaluation, I was given the opportunity to present my research findings to fellow student researchers and academic faculty in the format of a research conference, and later, I received international commendation in Dublin, Ireland in 2015.

This course gave me comprehensive, firsthand exposure as a researcher, allowing me to use the knowledge gained from my science courses in the lab and for clinical application. I gained in-depth insight into the full research process from the lab bench to publication, and I am grateful that I was able to work such a course and learning opportunity so conveniently into my schedule and university experience. Recognizing the value of the experiential learning from my own participation in research, I organised a student research conference at my university shortly after, with the goal of providing my peers with the same experiential learning opportunity. With over 300 students presenting their research and attending the event in its first year, it was exciting that students were enthusiastic about the conference and taking their learning to the next level through showcasing their research.

The point of this article is not to encourage educators to abandon didactic lecture style teaching and to switch to a new active learning method. In fact, didactic lecturing has been a pedagogical mainstay because it is an efficient method of delivering large volumes of information to many students in a classroom (Banning, 2005). However, didactic teaching, as with any other pedagogy, has its weaknesses and our current approach to education can be improved - and must be in order for education to remain relevant against the backdrop of a dynamic social and economic landscape, and above all, in order to empower students to take an active role in applying their knowledge and seeking their own learning opportunities long after they graduate. In today's classrooms, didactic learning can provide a framework or foundation for students' knowledge of facts, ideas, and theories, but it needs to be supplemented through more active, student-centred learning methods (Banning, 2005).

The integration of student-centred learning methods into curricula has been evaluated in numerous studies which found that actively engaging students in the classroom significantly encourages students to explore and experiment with their education and achieve academic success (Felder \& Brent, 1996; O’Neill \& McMahon, 2005). These findings are an indication of the enormous potential for educators and students alike to expand their outlook on what 'higher education' should look like, and take the initiative to actively facilitate and advocate placing the student at the center of learning incorporating a greater focus on student engagement. I believe there is an opportunity here to empower students to take leadership roles in their learning within the classroom, which should not simply be a space for memorizing and retaining information, but also a space for exploration and experimentation.

\section{Carving Your Own Path}

Aniqah Zowmi

Vicki Saunders (2014), in her book Think Like A SheEO, describes our world today: generations $Y$ and $\mathrm{Z}$ are instrumental in shaping a world in which we are creating millions of small companies that are each serving dozens of customers - in essence, we are creating a call to action for individuals to find their 
niche. However, traditional outlets of education are becoming outdated as they attempt to keep up with the boundless energy, passion, and innovation of Millennials, who are emphasizing intrinsic motivation and individual uniqueness to reshape educational institutions in order to prepare for the economy Saunders describes (Rickes, 2010). The 21st century has given rise to alternative education opportunities such as Quest University, Semester at Sea, Watson University, and Make School, among others; educational opportunities are emerging that allow learners to forego traditional education to shape their own ideas of learning. These opportunities present a paradigm shift within the educational sphere that must be harnessed to allow institutions to more effectively focus their programs and services on students - most prominently to keep students engaged throughout the learning process (McGlynn, 2008).

One aspect of the success of alternative institutions is providing students with the autonomy to create programs that are personally meaningful to the student in lieu of the current standard of coreheavy and elective-light curricula with little room for autonomy and exploration (Chirkov, 200). By allowing students to choose their projects, the questions they seek to answer, and the organizations they want to build, alternative models of higher education equip students with the autonomy to control their own learning, with outcomes such as "higher academic outcomes, better psychological well-being [...] less dropping out, and stronger persistence in educational settings" (Chirkov, 2009, p. 257). They are demonstrating first-hand to students the power they have to drive change in the world - no longer is one attending classes to collect information, but rather harnessing one's education to learn something that is "relevant to [students'] lives and that can make a difference in the world" (McGlynn, 2008, p. 21). There is room for educational institutions to provide students with the autonomy to shape their own education into meaningful, unique experiences that are personally relevant and intrinsically motivated.

I have always wanted to be a doctor, and I sought out a post-secondary institution which would offer me a strong Neuroscience program. In my first year at university, I was part of a team that initiated a speakers' series for youth within my university. I worked to project the voices of students on a public stage where these individuals would be able to share their passions with the community. Despite my formal education in science, I grew to love youth empowerment and leadership building through this experience of working with other students at my university. To be a part of building a supportive network that encouraged students to follow their passions and build the local community was immensely rewarding. I quickly realized that my passion lay in empowering others. A mission motivated by youth empowerment and community building was what had me waking up in the morning, getting out of bed, and saying to myself: "This is what I'm here to do."

Following this realization, I wanted to change my program of study to something that would be more applicable to and better prepare me for a career in youth empowerment and social engagement. Unfortunately, no formalized program in either discipline was available at my university nor at other nearby post-secondary institutions. Neither was there a way for me to 'create' a program that would allow me to obtain an undergraduate degree while maintaining autonomy over the courses I took. I found that I was not alone. More and more of my friends expressed to me this need to consolidate what drove them with what they were doing in school. There seemed to be very few, if any, opportunities for students to autonomously create their own programs. This lack of options led to my own disengagement from my program of study, as well as resentment towards post-secondary education. I believe that had there been opportunities for me to autonomously direct my undergraduate education, I would have enjoyed my experience by being able to learn something I felt would be applicable to my future career.

To prepare students to be successful, educational institutions need to provide more opportunities for education to be autonomous and intrinsically-motivated so that degrees become the result of meaningful experiences. Institutions tuning into the needs and personalities of students and the current societal structure will more effectively engage 
students to holistically embrace education: educational institutions can work to integrate servicelearning and experiential education with traditional education as formalized, flexible options for students to discover their passions (McGlynn, 2008). This flexibility could be achieved by integrating an individualized component to the degree or certificate program, providing students with the opportunity to harness passions, marry these passions with education, and take advantage of opportunities to put these passions and formalized education into practical applications (McGlynn, 2008).

Millennials are creating a societal paradigm shift that disrupts established education systems to become focused on students' intrinsic motivation (McGlynn, 2008). Flexibility in order to create meaningful educational experiences that embrace intrinsic motivation with autonomy and alternative learning opportunities will lead to student satisfaction (Chirkov, 2009). Providing post-secondary opportunities for students to embrace autonomy and intrinsic motivation will facilitate this paradigm shift in higher education that is sought by Millennials. Put simply, in order for students to harness their education in a meaningful way, they need to be engaged, and engaged by what makes them uniquely them - their passions.

\section{Bringing Students' Passions to the Forefront of Their Education}

\section{Vrindy Spencer}

The 2015 cohort of 3M National Student Fellows have the mantra "you do you," and our uniting theme is promoting student voices. Students welcome the challenge of finding their individual passions and voices both inside and outside the classroom. In my experience in the Canadian education system, our voices are not always heard. Often this results in disengaged students with glazed eyes and a hand on their cell phone. However, there are alternatives, such as self-directed learning, that would bring students' passions to the forefront of their education.

Self-directed learning is not new; in fact research on self-directed learning has been steadily growing over the past few years and includes didactic
(Jarvis, 2004), Socratic (Jarvis, 2004), and problembased learning (Tight, 2003). Part of the approach includes the understanding that learners are "capable of assuming increasing degrees of responsibility for their learning" (Brockett \& Hiemstra, 1991, p. 217). Self-direction does not necessitate a compromised quality of education (Brockett, 1988). Brockett and Hiemstra (1991) argue that institutions often lack the perspective that self-direction may be a more natural way to learn and therefore become set in their traditions. The rigidity of these structures may lose students on the way.

Throughout my 17 years of education, I have been sitting in classrooms in order to meet requirements for subjects I knew would not contribute to my personhood. I became an expert at memorizing, disseminating, and immediately afterwards clearing from memory all information presented to me. These standards in education did not go unnoticed by me. I learned to determine my self-worth based on the grades I achieved and how well I could predict what the teacher would request. I loved learning, yet I was not excited about sitting in front of professors who told me what to think rather than how to think. In fifteen years I went to nine different schools, not because I did not do well or fit into each institution, but because I was tired of just doing well and fitting in. I wanted a challenge. My story is not unique.

I have managed to reinvigorate my passion for education and learned to think critically by finding a supportive self-directed learning program. I have learnt the value of being taught not to memorize, but to understand. The word "education" has Latin roots related to "leading forth." Some Canadian institutions are adopting this concept. For example, the problem-based learning model at McMaster University involves small groups of students who work together to critically examine the material with the instructor facilitating and ensuring participation instead of transmitting knowledge. The model at Quest University Canada has a similar approach. Professors are called "tutors," because they guide discussions rather than lecture. Students formulate their own Question about the world and decide what 
they want to study instead of choosing an established major. Using this Question as a lens, students integrate academics into their personal life, thereby creating a perpetual sense of learning. An aspect of self-directed learning is to promote a lifelong learning perspective: "It has often been said that the purpose of adult education, or of any kind of education, is to make the subject a continuing, 'inner-directed' selfoperating learner" (Kidd, 1973). Students become more passionate about learning when they are given freedom to find what they want to learn and then are challenged to continue asking questions. In our higher education institutions, we should discuss the importance of obtaining an education, not just a degree. There is always more to learn and we should support an appreciation for the infinite process of discovering more about that which is impossible to fully understand.

I believe all institutions are capable of bringing students' passions to the forefront of their education. Students can and should be challenged to think about where their interests lie within each area of study. Programs and syllabi can be adapted to include individuals' passions. Students and teachers working together to create individualized learning agreements, such as learning contracts, enables the educational system and teachers to support and challenge students' learning.

While shifts in education take time, I challenge all who read this to make shifts in your life to incorporate more of your own passions. I ask you to orchestrate your own questions. It does not need to be something that encapsulates all of your interests, but instead to be a framework through which you want to view the world. When you find harmony, you encourage others around you to also find it. My second challenge is for you to play the instrument that best supports the melody of others in your teaching, learning, and life communities. I encourage you to find ways to bring students' passions to the forefront of their education and not to forget that everyone is a student, including you. Making space to express our separate instruments creates symphonies.

\section{The $21^{\text {st }}$ Century Classroom: Arts \& Strength Based Learning}

Wali Shah

As a literary artist, I find myself thinking in words. When I think about post-secondary education in the twenty first century, I envision words such as: 'inclusive,' 'creative,' and 'accepting.' As a student and member of the $3 \mathrm{M}$ National Student Fellows, I know that this generation of youth desire rich and diverse learning environments that challenge the status quo and embrace change. I consider myself to be a student both inside and outside the classroom. I feel that I have learned just as much, if not more, from life experiences as I have in a conventional classroom.

Education as we know it is changing. Technological advancements, student debt, and high tuition fees are among the issues that twenty-firstcentury education is facing. From personal standpoint, something that I feel is deserving of discussion in this era of change is the rare opportunity for undergraduate students to express their ideas in a way that highlights their strengths. In particular, the paucity of orality and arts-based assessments are of concern to me and to my peers. As a student who has always excelled in oral communication and enjoyed sharing my art in high-school, I am eager to continue utilizing my passions, strengths, and talents at the post-secondary level:

Learning can be deeper, wider and more powerful with the arts as a way to engage different ways of knowing. Students and practitioners/professionals alike, accessing the world through feeling and using our minds and bodies in more active and integrated ways allows expression and communication of ourselves. (van Den Akker, 2014, p. 2)

In large part, it is the arts and culture that make our campuses attractive and lively. It is often the students who are creative, talented, and artistic that our institutions take pride in featuring; yet, there 
are instances in which the students who drive our arts and culture have access to few arts-based assessments. I believe there should be more room for the arts in our classrooms. Educators who provide open-minded and inclusive opportunities allow students to combine their academic passion with their artistic passion. This inclusion not only enriches the quality of the work produced, but is also an enjoyable experience for both teachers and students. I believe that more structured and educational platforms should be on the agenda in terms of discussing what our classrooms look like in this era. The arts are a powerful tool. They allow students to express themselves in ways that the conventional essay may not. An open-minded teaching style also challenges educators to embrace the student perspective, and invites them to tune into a higher level of practice by being life-long learners as well.

In conjunction with the arts, I believe that enabling and developing oral skills are equally important. I have had classes in which the majority of my grade was based on writing and reading skills. In my experience, this has been true particularly in the first and second year university courses. I acknowledge that depending on various factors, such as an institution's student to teacher ratio, this suggestion may not be feasible. It is also important to note that many students who have transitioned from secondary school have already developed presentation skills. From a pragmatic perspective, offering more speaking opportunities to students can help to build a better understanding of what to expect in any professional occupation that requires presentation skills. I know that offering more oral presentations for course marks or giving the students a choice of written or oral assessments is an alternative that would be appreciated by students such as myself. It would allow students with varying strengths to succeed and would create a more equitable environment for all students striving to develop their potential.

I understand that some courses or programs may not have the flexibility to accommodate such requests, but I do think that we should embrace the opportunity to explore new ideas in teaching and learning while challenging comfort zones. I encourage educators to introduce arts-based assignments or engage students in curricula that enables them to present in front of their peers and to develop public speaking skills. My peers and I believe we need to be inclusive of all student strengths, instead of leaning heavily towards assessments that target only one skill set. I think that the purpose of education has always been to enable others to develop new skills, and help people grow in a variety of ways. Let's change what it means to be teaching and learning in the twentyfirst century, and tune into practicing the highest quality of teaching.

\section{Maximizing Effective Mentorship in Guided Experiential Learning}

Karen Young

When it comes to innovative ideas that aim to create real change on campus and beyond, offering mentorship opportunities for post-secondary students is one worthwhile investment. According to Kerka (1998), investing in mentorship opportunities that manifest in the form of guided experiential learning can trigger and perpetuate a cycle of students creating learning experiences that inspire other students to create their own. Kerka (1998) also states that guided experiential learning is the most effective type of mentorship, as it acknowledges both the "socially constructed nature of learning and the importance of experiential, situated learning experiences." (p. 3).

My involvement in service learning helped me understand the necessary inclusion of mentorship in experiential opportunities, and the importance of active reflection throughout the process. I noticed in my service learning placement that students were not given opportunities to lead in a mandatory course for all management students although the course title was "Leadership." For instance, one whole classroom session was designated for clarifying instructions, meaning that the assignment was either beyond their skill-level, the instructions themselves lacked clarity, or both. Since the course only entailed following instructions, students were not actually given the opportunity to lead. In other words, students were given the opportunity to reflect with their instructor's 
guidance without partaking in leadership roles or experiential learning. During the lecture-portion of the service learning course I took (with the other half focused on the placement), we learned much about the pedagogical value of experiential learning and reflection and less so on the techniques of how to practically reflect when in our placement. That is, the placement itself offered the experiential opportunity, but opportunities to develop skills of meta-learning were not there.

I recount my personal experiences in developing my skill sets for meta-learning which is "learning how to learn through reflection" (Strang, 2009, p. 248), and fostering tacit knowledge which knows "how to accomplish tasks well" (Mayfield, 2010, p. 2), by considering the inextricable link between mentorship and experiential learning. Mentorship can guide a student's learning to address gaps in the curriculum, such as understanding how to learn from experiential learning opportunities, both on and off campus. Mentorship can also guide students to apply insights gained from these opportunities, and encourages other students to become involved in active learning. In my case, mentorship guided me in my research regarding the mental health of undergraduate students; it also helped me establish a mental health magazine by and for students, which created experiential learning opportunities for my peers. It was through this series of experiences that I reflected on ways to maximize student opportunities for effective mentorship.

I also developed my meta-learning skill set while seeking mentorship to apply the knowledge I gained from an off-campus community event. I came to realize the value of maximizing exposure to social capital. One of the prominent experiences that prompted me to start a mental health magazine was an off-campus experience. At Mad Pride Toronto 2013, I listened to the Dean of Osgoode Law School declare that the law school will incorporate mental health components into their curriculum. I noticed that few people my age attended the event, which led me to question how undergraduate students would prepare themselves for this significant change in curriculum should other professional institutions adopt similar changes.
Anticipating the demand for mental health literacy in academic and professional preparation was subsequently discussed with someone whom I would consider and choose as a mentor. The opportunity to meet this individual occurred when I sought his expertise for budgeting while working on a TEDx event at our university. I discovered that this individual had worked for many years at Canada's largest teaching hospital for mental health and addiction, and is now working in higher education at my post-secondary institution. In light of his background, I consulted him about the idea of establishing a student mental health magazine to address the demand at the undergraduate level, both in terms of professional preparation and student wellbeing. He immediately understood the value of my idea. His insights were most useful in my reflection on how to move my idea forward.

I was able to draw on his expert advice because of serendipity. If student mentorship were formally structured into our educational system, then students could take advantage of not only the likelihood of finding mentors whose backgrounds are pertinent to students' interests and experiences, but also the opportunities for students to self-select their mentors. One way to accomplish this would be to provide students seeking experiential learning opportunities access to a database of mentors with relevant backgrounds.

The joining of my idea for a student mental health magazine with my idea of self-selected mentorship allowed me to go forward. After realizing that our post-secondary institution offered plenty of built-in mentorship, the first step in pursuing my goal was to establish a board of advisors with relevant experience to guide the creation of a student media platform for mental health. Knowing that I lacked the journalism experience, I recruited the director of the journalism program with an extensive background in radio journalism and a keen interest in minimizing effects of trauma among reporters. Not only was the combination of his background highly relevant to this endeavour, but he also acknowledged the need for the mental health magazine to remain a student-led project by emboldening and preparing me for the mission. In fact, he predicted that I would not be loved, but that I would be respected. With guidance 
on what to expect for the endeavour, he lifted and motivated me to pursue it.

All in all, maximizing exposure to social capital and allowing opportunities for self-selection of mentors are ways to augment students' selfdetermination to choose the most relevant and fitting expertise pertaining to the creation of their experiential learning opportunity. By leveraging and reorganizing what universities already haveextensive and diverse social capital-we are investing in the creation of guided experiential learning projects that eventually take on life cycles of their own. By reorganizing mentorship strategies to be more accessible and open to self-selection, we are ultimately investing in a meaningful kind of grassroots impact. By mobilizing experiential learning opportunities that nurture proximal learning, we are building a movement informed by experiences and a connected community. As a matter of fact, one of our current journalists read one of our articles on ADHD, went to the doctor, got diagnosed, felt better, got the support she needed, and, as a result, wanted to pay forward the opportunity to other students.

\section{Conclusion}

The theme of the Society for Teaching and Learning in Higher Education 2015 Conference, 'Achieving Harmony: Tuning into Practice,' reflects the collective call to action needed to reshape higher education for present and future generations. Responding effectively to the challenges facing postsecondary education systems today will require the coordinated efforts of policymakers, administrative leaders, educators, and students. The authors of this paper call for institutional changes within the postsecondary system that range from incorporating creative outlets in traditional course assessments to shifting paradigms in the way education is approached in order to be more inclusive of student passions and strengths. It is with the help of current educators and students tuning in to the needs and concerns of students that the education system can be improved in order to more effectively prepare students to create a better future.

\section{References}

Banning, M. (2005). Approaches to teaching: current opinions and related research. Nurse Education Today, 25(7), 502-508.

Brockett, R. \& Hiemstra, R. (1991). Self-direction in adult learning: Perspectives on theory, research, and practice. London and New York: Routledge. Retrieved from http://roghie mstra.com/sdlindex.html VIEW ITEM

Cantor, J. A. (1997). Experiential learning in higher education: Linking classroom and community. ERIC Digest, 1-6.

Chirkov, V. I. (2009) A self-determination theory perspective. Theory and Research in Education, 7(2), 253-262.

Felder, R. M. \& Brent, R. (1996). Navigating the bumpy road to student-centred instruction. College Teaching, 44(2), 43-47.

Frost, G. \& Connolly, M. (2015). The road less travelled? Pathways from passivity to agency in student learning. Collected Essays on Learning and Teaching, 8, 47-54. Retrieved from http://celt.uwindsor.ca/ojs/leddy/index .php/CELT/article/view/4264 VIEW ITEM

Gokhale, A. A. (1995). Collaborative learning enhances critical thinking. Journal of Technology Education, 7(1). Retrieved from https://scholar.lib.vt.edu/ejournals/JTE/v7n 1/gokhale.jte-v7n1.html VIEW ITEM

Jarvis. P. (2004). Adult education and lifelong learning: Theory and practice ( $3^{\text {rd }}$ ed.). London: Falmer Press.

Kerka, S. (1998). New Perspectives on Mentoring. ERIC Digest, 194, 1-7. Retrieved from http://files.eric.ed.gov/fulltext/ED418249.p df VIEW ITEM 
Kim, K. \& Bonk, C. J. (2006). The future of online teaching and learning in higher education. Educause Quarterly, 4, 22-30.

Knowles, M. S. (1975). Self-directed learning. New York: Association Press.

Light, R. J. (1992). The Harvard assessment seminars: Explorations with students and faculty about teaching, learning, and student life, second report. Cambridge, MA: Harvard University.

Mayfield, M. (2010). Tacit knowledge sharing: techniques for putting a powerful tool in practice. Development and Learning in Organizations: An International Journal, 24(1), 24-26.

McGlynn, A. P. (2008). Millennials in college: How do we motivate them? In Education digest: Essential readings condensed for quick review (pp. 19-21). Ann Arbor, MI: Education Digest.

McMullin, J. A., Cooke, M., \& Downie, R. (2004). Labour force ageing and skill shortages in Canada and Ontario. Canadian Policy Research Networks Incorporated (CPRN).

O’Neill, G., McMahon, T., \& McMulin, B. (2005). Student-centred learning: What does it mean for students and lecturers? Emerging Issues in the Practice of University Learning and Teaching (pp. 27-36). Dublin: AISHE.

Orlando, J. (2011, May 16). Failure is an option: Helping students learn from mistakes. Faculty Focus. Retrieved from http://www. facultyfocus.com/articles/teaching-and-learn ing/failure-is-an-option-helping-students-lea rn-from-mistakes/ VIEW ITEM

Pascarella, E. T., \& Terenzini, P. T. (1991). How college affects students: Findings and insights from twenty years of research. San Francisco: Jossey-Bass.
Rickes, P. C. (2009). Make way for Millennials! How today's students are shaping higher education space. Planning for Higher Education, 37(2), 7-17.

Saunders, V., \& Ryan, M. (2014). Think like a SheEO: Succeeding in the age of creators, makers and entrepreneurs. Toronto, ON: Barlow Book Publishing.

Siering, G. (2012). Why risk and failure are important in learning. http://citl.indiana.edu/news/dirfeb2012.php VIEW ITEM

Smith, K. A, Sheppard, S. D., Johnson, D. W., \& Johnson R. T. (2005). Pedagogies of engagement: Classroom based practices. Journal of Engineering Education, 94(1), 87101.

Strang, K. D. (2009). Measuring online learning approach and mentoring preferences of international doctorate students. International Journal of Educational Research, 48(4), 245-257.

Tight, M. (2003). Key Concepts in Adult Education and Training. Florence, KY: Routledge.

van den Akker, J. (2014). Art-based learning: Painting the journey of self-realisation. Reflective Practice: International and Multidisciplinary Perspectives, 15(6), 751765.

Vygotsky, L. (1978). The development of higher psychological processes. In Mind and Society (pp. 79-91). Cambridge, MA: Harvard University Press.

\section{Acknowledgements}

Although ten 3M National Student Fellows presented at the conference plenary, only six were able to contribute to this article. With the knowledge and 
experience shared by the rest of the National Student Fellows, it would be a disservice not to highlight their passion and experiences in the realm of education. We want to thank Jason Earl (Bishop's University), who showed real vulnerability by sharing his bravery confronting bullying in his deeply personal experience, and for using this as a springboard to embrace holistic, inclusive education. Thank you to Emilie McIntosh (St. Lawrence College) for her strong belief in personal responsibility, global food awareness, and the need for more education on the connections across economics, food, and social change. To Nicola Paviglianiti (Western University) for her commitment to the mind-body connection, meaningful service, and her drive to share these aspects of her life with us. Thank you to Navi Smith (University of Victoria) for her commitment to leadership development and sustainability of the environment through service learning that benefits both students and organizations working toward the betterment of the world. A sincere thank you to Kari Marken (University of British Columbia) and Natalie Gerum, who empowered us, as a cohort, to disrupt higher education through their passion, commitment, and honesty during our retreat. Finally, thank you to our cohort supervisor Dr. Maureen Connolly (Brock University) for her unfailing guidance throughout the process of writing this piece, and to Dr. Sarah King (University of Toronto, Scarborough) for her kind edits. Without these incredible people supporting us, we would not have been able to embrace wholeheartedly our own experiences with education, and we thank them for accompanying us on this journey.

\section{Biographies}

Piper Riley Thompson holds a Bachelor of Arts, with distinction, from Mount Allison University with majors in Sociology and Canadian studies. She has an abiding interest in positive public policy, civic engagement, and good governance. As a classical pianist, a member of University Senate, a theatre performer, and a vocal advocate for student mental health in post-secondary education, Piper is no stranger to taking risks and making mistakes and looks forward to a lifetime of learning.

Justine Baek recently graduated from Western University with a Bachelor of Medical Sciences and is currently pursuing a Doctor of Medicine at the University of Toronto. In 2014, Justine was selected the Head of State to present Canada's national delegation at the G20 Youth Summit to advocate for the address of global societal issues. She has recently partnered with the United Nations Association in Canada (UNAC) to spearhead the creation of their first youth platform, Connect. In Toronto, she writes as a student founder for Times Higher Education (THE) and is a coordinator for the national editorial board of the Foundation of Student Science and Technology (FSST). Justine strongly believes in the importance of building collaborative communities and promoting learning environments that encourage innovation and inclusivity.

Aniqah Zowmi is currently pursuing a Bachelor of Science in Neurobiology at Brock University. Her passion for youth empowerment and engagement have led to initiatives primarily with youth and education, including launching a speaking platform for students at Brock, BrockU Talks, and most notably representing Canada at the Commonwealth Youth Forum in 2015 in Malta to leverage the voices of youth around the Commonwealth to create real change. She has been recognized as one of Canada's 2015 Emerging Social Innovators by American Express and Ashoka, and hopes to pursue a career that involves equipping marginalized youth with the tools and skills to build sustainable communities.

Vrindy Spencer recently graduated with a Bachelor of Arts and Science degree from Quest University Canada. In place of a major, she studied the Question "What conditions optimize a sense of belonging?" Her interdisciplinary approach to this Question includes, but were not limited to, the fields of Psychology, Sociology, and Anthropology. She aims to build community, encourage authentic expression, and empower others to creatively explore passions in all spaces in which she finds herself. 
Wali Shah is a South Asian artist-educator currently studying Sociology at the University of Toronto, Mississauga. He was selected by Plan Canada as one of Canada's Top 20 Under 20 in 2014. He uses his art of spoken word poetry to discuss social issues and reach his audiences. To date, Wali has reached over 50,000 students and professionals through performance and public speaking and is currently a peer worker with a youth agency in Mississauga, ON. Wali is also an ambassador for the United Way, and has raised over $1 \$$ million dollars for The United Way of Peel by sharing his story with various high profile groups.

Karen Young is completing a Bachelor of Science Honours degree at the University of Toronto, Scarborough in psychology and health studies. Karen co-founded and co-chaired TEDxUTSC, the first campus-wide TEDx event at the University of Toronto; foundedMinds Matter Magazine (MMM), Canada's first interdisciplinary mental health magazine by students for students, their friends, and family; mentors newcomers to pass the Canadian citizenship test. As a nomadic learner, she loves bringing people together who might otherwise not meet. 


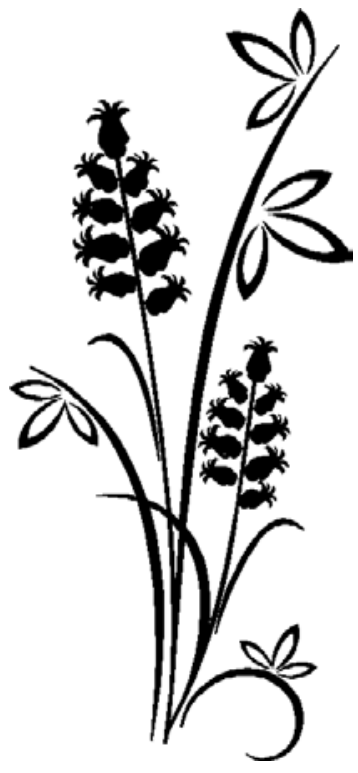

